\title{
Strategic Points in Aquaponics
}

\author{
Ranka Junge ${ }^{1, *}$, Bettina König ${ }^{2}$, Morris Villarroel ${ }^{3}$, Tamas Komives ${ }^{4,5}$ and M. Haïssam Jijakli ${ }^{6}$ \\ 1 Institute for Natural Resource Sciences, ZHAW Zurich University of Applied Sciences, \\ 8820 Waedenswil, Switzerland \\ 2 Humboldt-University of Berlin, Thaer Institute and IRI THESys, 10099 Berlin, Germany; \\ bettina-koenig@agrar.hu-berlin.de \\ 3 School of Agricultural Engineering, Technical University of Madrid, Ciudad Universitaria s/n, \\ 28040 Madrid, Spain; morris.villarroel@upm.es \\ 4 Plant Protection Institute, Hungarian Academy of Sciences, Centre for Agricultural Research, \\ Herman Otto 15, 1022 Budapest, Hungary; komives.tamas@agrar.mta.hu \\ 5 Faculty of Agricultural Science, Esterhazy Karoly University, Matrai ut 36, Gyongyos 3200, Hungary \\ 6 Integrated and Urban Plant Pathology, Gembloux Agro Bio-Tech, University of Liège, \\ 5030 Gembloux, Belgium; mh.jijakli@ulg.ac.be \\ * Correspondence: ranka.junge@zhaw.ch; Tel.: +41-58-934-5922
}

Academic Editor: Arjen Y. Hoekstra

Received: 2 December 2016; Accepted: 16 February 2017; Published: 3 March 2017

\begin{abstract}
Global environmental, social and economic challenges drive the need for new and improved solutions for food production and consumption. Food production within a sustainability corridor requires innovations exceeding traditional paradigms, acknowledging the complexity arising from sustainability. However, there is a lack of knowledge about how to direct further activities, to develop technologies as potential solutions for questions related to climate change, loss of soil fertility and biodiversity, scarcity of resources, and shortage of drinking water. One approach that promises to address these problems is controlled environment agriculture. Aquaponics (AP) combines two technologies: recirculation aquaculture systems (RAS) and hydroponics (plant production in water, without soil) in a closed-loop system. One challenge to the development of this technology is the conversion of the toxic ammonium produced by the fish into nitrate, via bacteria in a biofilter, to provide nitrogen to the plants. However, as this Special Issue shows, there are many other challenges that need to be addressed if the goal of the technology is to contribute to more sustainable food production systems.
\end{abstract}

Keywords: aquaponics; challenges; bacteria; sustainability

No living thing lives separate: One and Many are the same. [Johann Wolfgang Goethe, in "Epirrhema"]

In nature, nothing exists alone. [Rachel Carson in "Silent Spring"]

\section{Emerging Aquaponics}

Global environmental, social and economic challenges drive the need for new and improved solutions for food production and consumption [1]. Stable and sustainable food production requires continuous innovation in an attempt to achieve the goals of a circular economy [2,3]. However, there is a lack of knowledge about how to direct further activities, to develop technologies as potential solutions for questions related to climate change, loss of soil fertility and biodiversity, scarcity of resources, and shortage of drinking water.

This Special Issue is on aquaponics: one approach that promises to address these problems in the framework of controlled environment agriculture [4]. Aquaponics [5] combines two technologies, 
namely recirculating aquaculture systems (RAS) and hydroponics (plant production in water, without soil) in a closed-loop system (plants use the waste produced by the fish, thereby continuously cleaning the water). One major challenge to the development of this technology is to regulate the conversion of the ichthyotoxic ammonium produced by the fish, into nitrate, and to balance their concentrations in the fish tank and the plant growing beds. However, as this Special Issue shows, there are many other challenges that need to be addressed if the technology is to contribute to more sustainable food production systems.

Contemporary aquaponics started with the pioneering research of Todd, as referred to in [6] together with studies by Naegel [5] and Rakocy [7], with the first scientific papers being published around 1980. However, aquaponics research really took off only after 2010 (see the comparative number of scientific publications on hydroponics, aquaculture, and aquaponics in Figure 1). In spite of being acknowledged as one of the "ten technologies which could change our lives" by the European Union (EU) Parliament [8], research on aquaponics is still lacking. This is reflected by the number of peer-reviewed publications on aquaponics, which is significantly lower than in the fields of aquaculture, hydroponics or green roofs (Table 1). There is, however, a big difference between what the world is 'talking' about (as witnessed by the number of results in Google), and what is being thoroughly researched. In this regard, aquaponics can be termed "an emerging technology" and an emerging science topic.

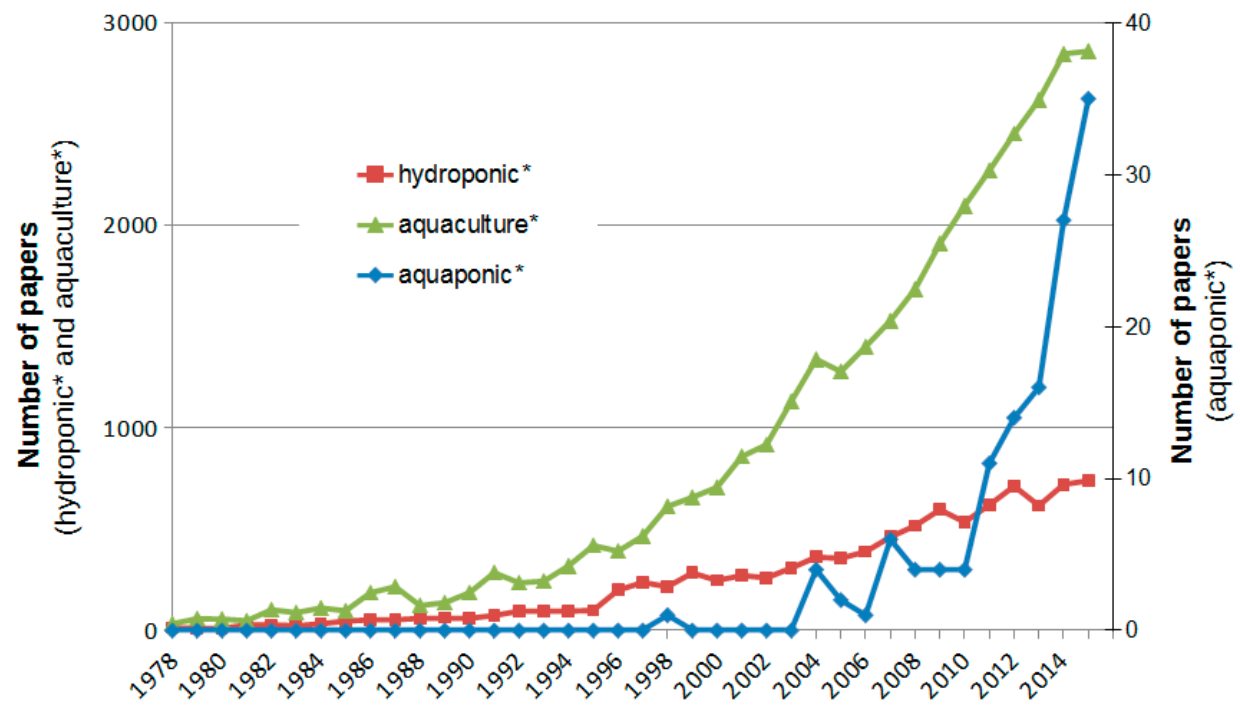

Figure 1. The number of papers published on hydroponic* ${ }^{*}$, aquaculture* ${ }^{*}$ and aquaponic ${ }^{*}$ from 1978 to 2015 (data were collected from the Scopus database on 17 September 2016). $¥$ Please note that the scale for aquaponic* is two orders of magnitude lower than hydroponic* or aquaculture*.

Table 1. Number of scientific publications according to Google Scholar for some environmental- and ecotechnologies (patents and citations excluded), compared to the number as indicated by search results in Google. The keywords were evaluated on 3 August 2016.

\begin{tabular}{cccc}
\hline Keyword & $\begin{array}{c}\text { Search Results on } \\
\text { Google }\end{array}$ & $\begin{array}{c}\text { Search Results on } \\
\text { Google Scholar }\end{array}$ & Hype Ratio * \\
\hline Aquaculture & $19,100,000$ & 916,000 & 21 \\
Aquaponics & $3,750,000$ & 2780 & 1349 \\
Building integrated agriculture & 5910 & 91 & 65 \\
Constructed wetlands & 422,000 & 39,100 & 11 \\
Green roofs & 450,000 & 18,500 & 24 \\
Hydroponics & $9,300,000$ & 70,900 & 131 \\
\hline
\end{tabular}


Table 1. Cont.

\begin{tabular}{cccc}
\hline Keyword & $\begin{array}{c}\text { Search Results on } \\
\text { Google }\end{array}$ & $\begin{array}{c}\text { Search Results on } \\
\text { Google Scholar }\end{array}$ & Hype Ratio * \\
\hline Membrane reactor technology & 5330 & 456 & 12 \\
Photovoltaic & $20,600,000$ & 825,000 & 25 \\
Recirculating aquaculture & 148,000 & 8600 & 17 \\
Wastewater-fed aquaculture & 2710 & 367 & 7 \\
\hline
\end{tabular}

Note: * Hype ratio: an indicator of the popularity of a subject in the public media in relation to the academic circles. Calculated as search results in Google divided by search results in Google Scholar.

Potentially, aquaponic systems can be designed for small, private installations to large commercial enterprises. Although many aquaponic systems may be found all over the world [6], the social, financial, environmental, operational, and ecological basics are in many aspects unknown or fuzzy, and the technology still needs further research and development in order to progress. The papers in this Special Issue of Water were written by research scientists working in different areas of closed system agriculture. The aim of this Special Issue is, therefore, to summarize and disseminate recent scientific findings in aquaponics. Special attention is paid to scientific progress leading to the development of a production system respecting the three pillars (social, environment and economy) of sustainability. The scope of this issue is ambitious, without being over-diluted. The successful development of aquaponics could insure, over the next decades, a greater part of the human food supply with a more neutral impact on the environment.

The aim of this paper is to sketch the diversity of fields that need to be addressed to further develop this food production approach; an attempt to decrease uncertainty and fuzziness by improving the knowledge base.

\section{Defining Types of Aquaponics}

Currently, the term aquaponics is used to describe a wide range of different systems with different goals. Nobody confuses professional aquaculture with home aquaria and koi ponds. Similarly, there ought to be a clear distinction between hobby forms of aquaponics (sometimes called backyard or household aquaponics), social projects (school aquaponics) [9], and commercial production [10]. Also, aquaponics can be part of urban agriculture, either as a small business or as a community project, or an element of rural agriculture (such as projects in the developing world). A comprehensive framework and a classification system is needed in that respect. One possible classification was suggested by Maucieri et al. [11], based on different design principles: main stakeholder, size, operational mode of the aquaculture compartment (RAS, flow through), water cycle management (coupled, de-coupled), water type, type of implemented hydroponic system and the use of space.

An aquaponic system can also address various goals or users, and has to be designed accordingly, with its components (fish tanks, biofilters, hydroponic units) fulfilling various requirements, such as pure food production, aesthetic purpose, education, hobby, etc. [12]. A classification can be attempted along these (sometimes contrasting) design guidelines, according to their main aspects.

Underlying these broad characterizations, there are several technological and biological implications. Consider a classification based on operational modes. There are two main categories: extensive (with integrated sludge usage) and intensive (with sludge separation) [11,13]. Whilst the integrated sludge usage allows for complete nutrient recycling, the negative aspects include limited fish stocking, turbid water, and rather low biofilter performance. On the other hand, sludge separation enables up to five times more intensive fish stocking, with positive aspects which include clear water, lower BOD (biochemical oxygen demand), lower microbial load and optimized biofilter performance. On the negative side, there is only partial nutrient recycling, unless additional provisions are taken (such as integration of a biodigester unit) [14]. An additional sludge treatment step (on-site or off-site) such as connecting sludge biodigesters or vermicomposting, may be necessary. 
Currently, there is some debate about the advantages of circulating, or coupled vs. decoupled aquaponics [14]. There is not yet a consensus about the status of decoupled systems since they could be considered as just another plant fertigation method (i.e., as long as the water does not circulate back to the fish).

\section{What Roles Can Aquaponics Play in Society?}

Whilst aquaponics can involve a wide array of users, one aquaponics facility cannot target all of them at the same time. There are several trade-offs involved. Therefore, the user group ought to be identified before design is completed. For example, a commercial operation, selling to retailers, needs to comply with many legal requirements [15]. Whilst, on the other hand, if aquaponics is to contribute to community wellbeing, for which it has immense potential, it has to be designed to be entirely or partly operated by non-professionals, either alone or under professional guidance. One example is a passive aquaponics house operated by the social living facility "Somogy County Association of Disabled Persons" [16]. The architecture was adapted to the needs of the facility, allowing for disabled access.

Aquaponics has features that are well suited to urban environments, or areas where land is scarce or polluted, as well as in rural areas $[17,18]$. It allows intensive production in small spaces, producing fresh and high quality food, can contribute to urban heat island mitigation [19], can use harvested rain water, and thus acts as a reservoir in case of large rain events.

Aquaponics must rely on environmentally friendly methods of pest and disease control, because otherwise the health of the fish would be negatively affected. In plant production, biocontrol or integrated pest management can be implemented [20]. However, the use of hormones or antibiotics in fish rearing is not allowed.

Existing RAS units can also be upgraded to include aquaponics, such as using wastewater from aquaculture to feed hydroponic systems, or the other way around, adding RAS to a vegetable grower's operation. An example of the first solution is described by Bulc et al. [21], who diverted some water from a small-scale cyprinid fish farm into an aquaponic system with a vertically constructed wetland planted with tomatoes (Lycopersicum esculentum L.). An example of the second solution is the "bolt-on" system by UrbanFarmers Company, which enables the seamless integration of a RAS unit into an existing hydroponic system [22].

The design of successful aquaponics systems depends on the user group. High-yield, soil-less production requires high input of technology (pumps, aerators, loggers) and knowledge, and is therefore mostly suited for commercial operations. A good example of this is the newly opened rooftop farm by UrbanFarmers in Den Haag [23]. However, it is entirely possible to design and operate low-tech aquaponics systems that require less skill to operate, and still yield respectable results $[13,24]$. The range of applications implies different points for further development pathways for the technology, system design and socio-economic aspects, which we discuss in the following sections.

\section{What Trends Can Be Expected in the Development of Aquaponics?}

\subsection{Trends in Technology}

The trade-offs mentioned above suggest that aquaponic technology might develop in at least two directions: on the one hand towards low-tech solutions (probably mostly in developing countries and for hobbyists), and on the other hand towards highly efficient hi-tech installations (predominantly in developed countries and with professional/commercial partners).

While the technology itself does not pose limits to an area of the farm (because it can be modular), the size of urban farms is determined by (i) the characteristic of the available area, which is necessarily fragmented in a city (brownfield sites, underutilized buildings and rooftops); (ii) the constraints posed by required crop production to achieve the targeted result. As a rule of thumb, the area required to 
break even for commercial operations is around $1000 \mathrm{~m}^{2}$ [25]. Hobby and backyard installations can of course be much smaller.

Aquaponics farms can grow/expand by increasing the number of operating systems (or modules) or by going vertical: although they cannot be scaled up too far without steeply increasing construction and energy costs. The size range of urban aquaponic farms will probably range between $150 \mathrm{~m}^{2}$ and $3000 \mathrm{~m}^{2}$, due to space, economic and management limitations, which could cover the basic requirements for an assortment of fresh vegetables for part of the urban population. Peri-urban aquaponic farms could be larger and adjusted to include inland aquaculture systems or to re-use nutrient rich effluent, composted fish sludge and/or biochar in rural areas.

Aquaponic technology itself can be considered immature, since there are still problems to be solved. Simply linking a state-of-the-art aquaculture with a state-of-the-art hydroponics system does not take into account other factors, such as problems with clogged drum filters, non-efficient settlers, oxygen failures, poorly designed settlers, or clogged water pipes. Even though the influence of plant growing beds (NFT, drip irrigation, deep water culture) is already well known in hydroponic systems, the choice of those beds in aquaponic systems needs to be further studied since it will have consequences on productivity and operation.

Further research is required in other areas as well. Since microorganisms are ubiquitous, they play an important part in all stages of aquaponic production. The influence of environmental conditions on their abundance, diversity and roles could be investigated, e.g., by further using Novel Generation of Sequencing Methods [26,27]. One of the central questions is appropriate pest and disease control. Problems related to plant protection in aquaponics were raised and briefly discussed by Bittsanszky et al. [20] and Goddek et al. [28]. Those authors conclude that since very few tools are available for plant protection in aquaponics, emphasis should be placed on precautionary measures to minimize the infiltration of pests and pathogens.

If aquaponics is to be developed as a successful high-tech method for food production, one focus will need to be on reducing manpower requirements. Some automation is already well developed (watering and feeding, online monitoring and alarms for many parameters, especially oxygen), however it needs to be refined to allow more precision and labor efficient operations. The steps to take are (i) selection, development and implementation of relevant sensors; (ii) data analysis and modeling; and (iii) development in automation.

\subsection{Trends in Systems Design}

While aquaponics has the potential to be sustainable, comprehensive life cycle analysis (LCA) studies of aquaponic operations and products are scarce [28-30]. However, it is clear that the ecological impact of aquaponics could be further improved by tapping into renewable sources of energy, developing daylight harvesting methods to avoid the use of electrical energy, using pre-treated or recycled water or rainwater, and improving the climate control of greenhouses. In an urban environment, aquaponics ought to be further integrated into buildings, allowing for gas, water and energy exchange between greenhouses and buildings. One example is the ICTA-ICP Rooftop Greenhouse Lab (RTG-Lab) in Spain [31].

Improvements are also needed regarding organic material cycles. Fish feed is the main nutrient input and defines, to a large extent, the sustainability of the operation. Aquaponics (just like RAS) requires optimal nutrition for fish, and the fish feeds should consist of sustainable, locally sourced materials (organic, vegetarian, insects). The aquaponic loop should be further closed by digesting the fish sludge to re-use the nutrients in the aquaponic system [32] or rearing redworms and/or insects on plant residues and using these for fish feed, with the residual fish sludge and plant waste being composted. The goal is to arrive at a zero-waste concept on the farm in order to reduce the aquaponic footprint. Studies on the greenhouse gas emissions could make this picture complete [33].

Finally, the possibility of using novel organisms in aquaponics (e.g., terrestrial and aquatic plants, fresh water as well as marine fish, algae and seaweeds, crustaceans etc.) should be further explored to 
expand the ecological cycle. Also, new aquaculture and plant products could have implications on the economic viability of the technology as the following section discusses.

\subsection{Socio-Economic Trends}

Currently, aquaponics is a small but emerging business sector that attracts more and more capital. Although food production is the basic goal of the operation, it is currently combined with tourism and education in order to improve profitability. Because of its relatively novel technological cross-cutting approach, aquaponics has no clear legal status within the existing regulation in Europe [15]. Whilst in the US, aquaponics can be certified as organic, in Europe this is currently not possible because of the soil-less plant production and due to high stocking rates [34]. Despite the potential that aquaponic technology carries for social acceptance (because of its approach to be a low-waste method of food production that conserves water, creates jobs, and contributes to the local economy), there are still open questions. Only a few studies have addressed societal and consumer acceptance (e.g., [35], indicating high acceptance in Malaysia and [36] less acceptance in Germany). Factors such as knowledge, values, beliefs, cultural and social norms, food traditions and trends, food shopping and preparation need to be understood in different AP systems' cultural and market settings. As we have shown above, AP is a relevant topic in social media, but little is known about consumer knowledge and behavior. Also, we still do not understand how it is perceived in comparison with organic or conventional production, in terms of convenience or health product categories. In general, we do not know enough about how the sustainability advantages of AP should be communicated to consumers, compared to product quality such as taste, freshness, health and price [37].

To date, only a few aquaponic systems are being used for purely commercial production [10,38]. Communicating sustainability expectations is one of the early income sources of aquaponic companies. Yet, to date, no in-depth studies are available on their economic performance and socio-economic impacts on the local economy, beyond the expectations associated with the technology.

$\mathrm{Up}$ to now, most research on AP has focused on developing functional facilities. One way to improve profitability can be to improve efficiency. Efficient use of alternative energy sources, water and the recycling of organic effluents will save on production costs, but needs to be evaluated against higher investment costs. To increase commercial production, novel business models must also be developed in relation with the emerging ideas of circular and local economies, yet managing interfaces increases complexity. Here, questions of framework conditions for operating costs, of local logistics and determinants of vegetable and fish shopping behavior will need to be addressed. Besides technological efficiency improvement, operational management questions also exist and new transport-sensitive varieties could be interesting to explore for obtaining a sufficiently high market price by avoiding price competition with specialized horticulture. However, combining a new technology with new products also increases entrepreneurial uncertainty.

Aquaponics is especially useful for educators: even a small classroom system offers a wide array of possibilities for instruction at different educational levels, from primary school to university [12]. Aquaponics can easily be integrated into all STEM (science, technology, engineering and mathematics) subjects, not only to demonstrate basic biological and ecological principles, but also chemistry, physics and mathematics. A variety of competencies and skills can be gained by operating aquaponics, such as basic lab skills, team work, environmental ethics, to name but a few. Aquaponics has also been shown to foster systems thinking [39] and creativity. Yet, the specific organizational settings and curricula need to be considered and the impact needs to be better understood [9].

The width of socio-economic aspects outlined here illustrates that aquaponics will only flourish with a broad collaboration of several additional key players beyond natural scientists and engineers. This could include, for example, (1) designers and architects to provide useful and aesthetically pleasing designs; (2) social scientists to help understand perceptions and acceptance of aquaponics among a wider audience; and (3) health and nutritional sciences to explore how aquaponic products could be incorporated into diets as healthy and sustainably produced food. Also, feedback loops to 
system developers and plant and fish physiologists need to be organized to improve systems with regard to consumer demand, sustainability effects and the nutritional value of the products.

Last but not least, aquaponics fosters food innovation. Chefs and bloggers can provide new recipes and ideas for new produce, which might give new impulses for the development and diffusion of the technology.

\section{Conclusions}

In conclusion, our knowledge of the factors that determine the commercial viability of aquaponics has expanded greatly in recent years, and it is our conviction that this technology has the potential to play a significant role in food production in the future. However, there is much yet to be learned about the environmental, operational, and socio-economic effects of aquaponics. The points raised in our contribution illustrate that additional research is not only needed on the biological and technological system per se (for example, the microbiome of the system), but should also involve system design and socio-economic aspects and their interrelation for developing AP as a technology contributing to more sustainable food systems.

Acknowledgments: In this Editorial, we could only quote the most recent references; therefore, we apologize to those researchers whose equally important works were not cited. We thank the anonymous referees for their valuable suggestions, which improved the final form of this paper. Special thanks to Andreas Graber, co-founder of UrbanFarmers, for fruitful discussions. This work was partly supported by funding received from the COST Action FA1305 “The EU Aquaponics Hub—Realising Sustainable Integrated Fish and Vegetable Production for the EU".

Author Contributions: The review was initiated within the framework of the COST Action FA1305. Ranka Junge wrote the first version of the manuscript. Other authors provided inputs and participated in discussions. All authors read and approved the final manuscript.

Conflicts of Interest: The authors declare no conflict of interest.

\section{References}

1. United Nations, Department of Economic and Social Affairs, Population Division. World Population Prospects: The 2015 Revision, Key Findings and Advance Tables; Working Paper No. ESA/P/WP.241; United Nations: New York, NY, USA, 2015.

2. Leach, M.; Rockström, J.; Raskin, P.; Scoones, I.; Stirling, A.C.; Smith, A.; Thompson, J.; Millstone, E.; Ely, A.; Arond, E.; et al. Transforming Innovation for Sustainability. Ecol. Soc. 2012, 17, 11. [CrossRef]

3. Pretty, J.; Sutherland, W.J.; Ashby, J.; Auburn, J.; Baulcombe, D.; Bell, M.; Bentley, J.; Bickersteth, S.; Brown, K.; Burke, J.; et al. The top 100 questions of importance to the future of global agriculture. Int. J. Agric. Sustain. 2010, 8, 219-236. [CrossRef]

4. Kiss, G.; Jansen, H.; Lucia Castaldo, V.; Orsi, L. The 2050 City. Procedia Eng. 2015, 118, 326-355. [CrossRef]

5. Naegel, L.C.A. Combined production of fish and plants in recirculating water. Aquaculture 1977, 10, 17-24. [CrossRef]

6. Love, D.C.; Fry, J.P.; Genello, L.; Hill, E.S.; Frederick, J.A.; Li, X.; Semmens, K. An international survey of aquaponics practitioners. PLoS ONE 2014, 9, e102662. [CrossRef] [PubMed]

7. Rakocy, J.E.; Allison, R. Evaluation of a closed recirculating system for the culture of tilapia and aquatic macrophytes. In Proceedings of the Bio-Engineering Symposium for Fish Culture; Allen, L.J., Kinney, E.C., Eds.; Publication No. 1; American Fisheries Society: Bethesda, MD, USA, 1981; pp. 296-307.

8. Van Woensel, L.; Archer, G.; Panades-Estruch, L.; Vrscaj, D. Ten Technologies Which Could Change Our Lives; European Union: Brussels, Switzerland, 2015.

9. Hart, E.R.; Webb, J.B.; Danylchuk, A.J. Implementation of Aquaponics in Education: An Assessment of Challenges and Solutions. Sci. Educ. Int. 2013, 24, 460-480.

10. Buehler, D.; Junge, R. Global Trends and Current Status of Commercial Urban Rooftop Farming. Sustainability 2016, 8, 1108. [CrossRef]

11. Maucieri, C.; Forchino, A.; Nicoletto, C.; Junge, R.; Pastres, R.; Sambo, P.; Borin, M. Life cycle assessment of a micro aquaponic system built using recovered material and usable for education purposes. J. Clean. Prod. 2017, submitted. 
12. Graber, A.; Antenen, N.; Junge, R. The multifunctional aquaponic system at ZHAW used as research and training lab. In Proceedings of the Conference VIVUS: Transmission of Innovations, Knowledge and Practical Experience into Everyday Practice, Strahinj, Slovenija, 14-15 November 2014.

13. Sommerville, C.; Cohen, M.; Pantanella, E.; Stankus, A.; Lovatelli, A. Small-Scale Aquaponic Food Production-Integrated Fish and Plant Farming; No. 589. FAO Fisheries and Aquaculture Technical Paper; Food and Agriculture Organization of the United Nations: Rome, Italy, 2014.

14. Goddek, S.; Espinal, C.A.; Delaide, B.; Jijakli, M.H.; Schmautz, Z.; Wuertz, S.; Keesman, K.J. Navigating towards decoupled aquaponic systems: A system dynamics design approach. Water 2016, 8, 303. [CrossRef]

15. Joly, A.; Junge, R.; Bardocz, T. Aquaponics business in Europe: Some legal obstacles and solutions. Ecocycles 2015, 1, 3-5. [CrossRef]

16. Passive Aquaponics. Available online: https://www.facebook.com/PassiveAquaponics (accessed on 11 September 2016).

17. McClinton, N.; Cooper, J.; Khandeshi, S. Assessing the potential contribution of vacant lands to urban vegetable production and consumption in Oakland, California. Landsc. Urban Plan. 2013, 111, 46-58. [CrossRef]

18. Specht, K.; Siebert, R.; Hartmann, I.; Freisinger, U.B.; Sawicka, M.; Werner, A.; Thomaier, S.; Henckel, D.; Walk, H.; Dietrich, A. Urban agriculture of the future: An overview of sustainability aspects of food production in and on buildings. Agric. Hum. Values 2014, 31, 33-51. [CrossRef]

19. Zinzi, M.; Agnoli, S. Cool and green roofs. An energy and comfort comparison between passive cooling and mitigation urban heat island techniques for residential buildings in the Mediterranean region. Energy Build. 2012, 55, 66-76.

20. Bittsánszky, A.; Gyulai, G.; Junge, R.; Schmautz, Z.; Komives, T. Plant protection in ecocycle-based agricultural systems: Aquaponics as an example. In Proceedings of the 28th International Plant Protection Congress (IPPC), Berlin, Germany, 24-27 August 2016.

21. Bulc, G.T.; Šajn Slak, A.; Kompare, B.; Jarni, K.; Krivograd Klemenčič, A. Innovative Aquaponic Technologies for Water Reuse in Cyprinid Fish Farms. In Proceedings of the BALWOIS 2012, Ohrid, Republic of Macedonia, 28 May-2 June 2012.

22. UrbanFarmers. Available online: https://urbanfarmers.com/productsservices/uf-bolt-on-systems/ (accessed on 7 November 2016).

23. UrbanFarmers Benelux. Available online: http://www.urbanfarmers.nl/en/our-farms/uf002-de-schilde/ (accessed on 9 December 2016).

24. Trang, N.T.D.; Brix, H. Use of planted biofilters in integrated recirculating aquaculture-hydroponics systems in the Mekong Delta, Vietnam. Aquac. Res. 2014, 45, 460-469. [CrossRef]

25. Graber, A.; Urban Farmers AG, Zürich, Switzerland. Personal communication, 2016.

26. Massart, S.; Martinez-Medina, M.; Jijakli, H. Biological control in the microbiome era: Challenges and opportunities. Biol. Control 2015, 89, 98-108. [CrossRef]

27. Schmautz, Z.; Graber, A.; Jaenicke, S.; Goesmann, A.; Junge, R.; Smits, T.H.M. Microbial diversity in different compartments of an aquaponics system. Arch. Microbiol. 2016. [CrossRef] [PubMed]

28. Goddek, S.; Delaide, B.; Mankasingh, U.; Ragnarsdottir, K.V.; Jijakli, H.; Thorarinsdottir, R. Challenges of sustainable and commercial aquaponics. Sustainability 2015, 7, 4199-4224. [CrossRef]

29. Konig, B.; Junge, R.; Bittsanszky, A.; Villarroel, M.; Komives, T. On the sustainability of aquaponics. Ecocycles 2016, 2, 26-32. [CrossRef]

30. Palm, H.W.; Bissa, K.; Knaus, U. Significant factors affecting the economic sustainability of closed aquaponic systems. Part II: Fish and plant growth. AACL Bioflux 2014, 7, 162-175.

31. Sanyé-Mengual, E.; Llorach-Masana, P.; Delmás, D.S.; Oliver-Solà, J.; Josa, A.; Montero, J.I.; Rieradevall, J. The ICTA-ICP Rooftop Greenhouse Lab (RTG-Lab): Closing metabolic flows (energy, water, $\mathrm{CO}_{2}$ ) through integrated Rooftop Greenhouses. In Finding Spaces for Productive Cities, Proceedings of the 6th AESOP Sustainable Food Planning Conference, VHL University of Applied Sciences, Velp, The Netherlands, 5-7 November 2014; IUFN: Paris, France, 2014; pp. 692-701.

32. Goddek, S.; Schmautz, Z.; Scott, B.; Delaide, B.; Wuertz, S.; Junge, R. The Effect of Anaerobic and Aerobic Fish Sludge Supernatant on Hydroponic Lettuce. Agronomy 2016, 6, 37. [CrossRef]

33. Hu, Z.; Lee, J.W.; Chandran, K.; Kim, S.; Brotto, A.C.; Khanal, S.K. Effect of plant species on nitrogen recovery in aquaponics. Bioresour. Technol. 2015, 188, 92-98. [CrossRef] [PubMed] 
34. USDA Organic Certification of Aquaponics Systems. Available online: https://www.friendlyaquaponics. com/organic-certification/ (accessed on 4 February 2017).

35. Tamin, M.; Harun, A.; Estim, A.; Saufie, S.; Obong, S. Consumer Acceptance towards Aquaponic Products. J. Bus. Manag. 2015, 17, 49-64.

36. Specht, K.; Weith, T.; Swoboda, K.; Siebert, R. Socially acceptable urban agriculture businesses. Agron. Sustain. Dev. 2016, 36, 17. [CrossRef]

37. Newman, G.; Gorlin, M.; Dhar, R. When Going Green Backfires: How Firm Intentions Shape the Evaluation of Socially Beneficial Product Enhancements. J. Consum. Res. 2014, 41, 823-839. [CrossRef]

38. Love, D.C.; Fry, J.P.; Li, X.; Hill, E.S.; Genello, L.; Semmens, K.; Thompson, R.E. Commercial aquaponics production and profitability: Findings from an international survey. Aquaculture 2015, 435, 67-74. [CrossRef]

39. Junge, R.; Wilhelm, S.; Hofstetter, U. Aquaponic in classrooms as a tool to promote system thinking. In Proceedings of the Conference VIVUS: Transmission of Innovations, Knowledge and Practical Experience into Everyday Practice, Strahinj, Slovenija, 14-15 November 2014; pp. 234-244.

(C) 2017 by the authors. Licensee MDPI, Basel, Switzerland. This article is an open access article distributed under the terms and conditions of the Creative Commons Attribution (CC BY) license (http:/ / creativecommons.org/licenses/by/4.0/). 